\title{
Self-leadership traits of academics to conform to a changing higher- education environment
}

\author{
K Jooste, ${ }^{1} \mathrm{PhD} ; \mathbf{J}$ Frantz, ${ }^{2} \mathrm{PhD}$ \\ ${ }^{1}$ Department of Nursing Science, Faculty of Health and Wellness, Cape Peninsula University of Technology, Cape Town, South Africa \\ ${ }^{2}$ Department of Physiotherapy, Faculty of Community Health, University of the Western Cape, Cape Town, South Africa
}

Corresponding author: J Frantz (jfrantz@uwc.ac.za)

Background. Now, perhaps more than ever, leadership is seen to be associated with those who manage to create and promote a compelling and meaningful sense of their own values and identity that is demonstrated in the traits they portray to followers. In higher-education sectors, 'leadership at all levels' refers to both those in formal roles, such as departmental chairpersons, and those in informal roles, such as postgraduate-degree supervisors or mentors.

Objectives. To explore academics' experiences of their self-leadership traits in a higher-education institution in a changing educational environment. Methods. A qualitative, exploratory, descriptive and contextual research design was followed. The study population consisted of senior academics in departments in the Faculty of Community and Health Sciences at a residential university in South Africa. Purposive convenience sampling was used to include 10 available participants, all vice deans or heads of department, after which data saturation occurred. Individual interviews were conducted that lasted around approximately 45 minutes. The data were analysed using open coding.

Results. Five themes emerged around leadership: its development over time; that it can be earned though different means; that it is influenced through personal experience; the role of role models; and environmental encouragement.

Conclusion. The study findings indicated different views on the development of leadership skills. Participants commented on the importance of a complex blend of competencies needed by leaders. A number of suggestions were put forth on how to develop leadership skills.

Afr J Health Professions Educ 2017;9(4):199-202. DOI:10.7196/AJHPE.2017.v9i4.823

Leaders in higher education are required to address the imperatives for change that come from extrinsic sources, as well as from intrinsic pressure that results from the growth of knowledge itself. Academics need to have the confidence to exert their power and be at the forefront of leading other people towards the actualisation of the objectives of a team. ${ }^{[1]}$ In the highereducation sector, visible leadership is usually expected both from people in formal roles, such as heads of school, departmental chairpersons or deans, and those in informal roles, such as postgraduate-degree supervisors who are beginning to master self-leadership. Persons engaging in self-leadership frequently cultivate a sense of ownership in terms of their tasks and work processes. As a result, self-leading individuals may demonstrate higher levels of commitment to their tasks, goals, teams, or organisations than individuals who do not engage in self-leadership. ${ }^{[1]}$

In order to understand self-leadership, one needs to have insight into how one is classified as a leader in higher education, whether the role is formal or informal, whether the leader exerts an intentional influence or is it determined by context, and how leadership is embodied in individuals. ${ }^{[2]}$ One must first be able to lead oneself before leading others. Perceptions of who leads, and why they lead, are as important as what they do and how and where they do it. Now, perhaps more than ever, leadership is seen to be associated with those who manage to create and promote a compelling and meaningful sense of their own values and identity. This is nothing unique to higher education, but the way in which it must be accomplished is highly context-specific. ${ }^{[3]}$

Self-leadership of academics fundamentally refers to being driven by motivation and self-influence to direct oneself towards achieving optimum performance in a situation. ${ }^{[1]}$ Leadership should be from within, and can thus be defined as 'authentic self-expression that creates value. ${ }^{[4]}$ This form of leadership can thus be identified at all levels of an organisation. Leadership cannot be removed from the culture of an organisation. The philosophy of the Faculty of Community and Health Sciences at a higher-education institution in South Africa (SA) focuses on developing leaders at all levels who are able to adapt, collaborate and work within diversity, and who can lead themselves. As it had not been previously studied, it was unclear how academics experienced their selfleadership in their day-to-day challenges as senior academics. Thus the aim of this study was to explore experiences of academics in a highereducation institution of their self-leadership traits in an educational environment.

The study was conducted within Cashman's ${ }^{[4]}$ theoretical framework of seven pathways for an academic, as it was considered relevant to the specific concept of self-leadership and to the context of academics in this study, focusing on leading from the inside out.

\section{Methods \\ Study design}

This study used a qualitative, exploratory, descriptive and contextual research design. This design provided insight into the experiences of academic self-leaders in a changing higher-education environment, obtaining rich data and an in-depth understanding of the phenomenon, namely self-leadership. 


\section{Setting and study population}

The study population consisted of all senior academic leaders in the Faculty of Community and Health Sciences at a residential university, in the disciplines of physiotherapy, occupational therapy, dietetics, psychology, social work, sport, recreation and exercise science, natural medicine, nursing and public health. Purposive convenience sampling was used, and 10 participants, occupying the roles of deans, heads of department (HODs) and directors of schools and academic units, were selected until data saturation occurred, when no new data emerged.

\section{Data collection}

Individual semi-structured interviews were conducted that lasted approximately 45 minutes. The interviews were tape-recorded and held in a private room.

\section{Data analysis}

The data were analysed through open coding, to identify themes and categories. The authors and independent coder reached consensus on the themes that emerged from the data.

\section{Ethical considerations}

This study received ethics clearance (ref. no. 23/4/2015) from the Senate Research and Ethics Committee at a university in the Western Cape, SA. All participants signed a written consent form after receiving information on the purpose of the study. They could withdraw from the study at any stage. The interviews conducted were confidential, and names did not appear on the transcripts.

\section{Results}

Seven themes emerged that corresponded to the self-leadership skills outlined by Cashman: ${ }^{[4]}$

\section{Developing awareness and mindfulness of character and personality (personal mastery)}

Self-awareness can be described as adopting a strong orientation toward achievement, holding high expectations for yourself and others and pushing yourself and others to achieve at high levels. ${ }^{[5]}$ One participant mentioned that he focused on discovering himself while being mindful of his abilities:

'We can be aware of what is a leader, a leader should do, should do this, and this, and this, you should manage, you should do this, you should manage time, you should [...] but I think leadership is also discovering of yourself, and your abilities.'

Another participant was aware of his inner self (inner consciousness), which he said contributed to his leading of others:

'So I think a lot of my drive and a lot of my work starts with my inner work and I do believe that things work from the inside out, and if I'm on top of my game my inner world then the outer world follows, then I'm able to provide the leadership, then I'm able to be the role model.'

One of the participants also mentioned that leadership characteristics should be developed within a person, and that this development takes time:

'So I think there are certain skills that, or values that [are] inbred in the person that makes them a leader, but there are also certain skills that need to be developed within a person.'
Another participant indicated that the changes in personality and characteristics of a developing leader were bound by the environment or context:

'That people can learn those skills and that quite often what emerges as leadership qualities is dependent on the environment in the context in which the individual finds themselves.'

\section{The importance of actions having a purpose (purpose mastery)}

Purpose mastery acknowledges creating a vision and figuring out where the organisation is heading, and getting people moving in that direction. ${ }^{[5]}$

An HOD mentioned having a vision, with a clear plan of the actions that were needed to move forward:

'On the one hand, is that the person should have a vision. $\mathrm{He}$ should know where he takes the people to, and then of course you should have an idea how to get there [...] The vision is to make this department the best department [...] but should be realistic [...] you should have a clear path on how you can get there, and all the things you should put in place to get there.'

Another participant mentioned setting clear goals (purpose) through mentorship and coaching:

'So I think that mentorship and coaching is very important. I think that peer networks, sharing, getting people doing similar things. Setting goals, goal setting, you know.

\section{From problem focus to opportunity (change mastery)}

Effective leaders should not lose sight of their long-term vision in the midst of change. ${ }^{[4]}$ One participant realised that in the past there were limitations in the higher-education sector, and mentioned that changing oneself to act as a leader was better for the future:

'I think everybody is protecting their own territory [...] It comes from the past where they needed to do that and if we are able to move outside of our silos and move into, if everybody realises that they are a leader and they are promoting, for example, the faculty $[. .$.$] then we$ would start moving better.'

Also, being aware of change, and able to adapt, is needed on different levels, and it was mentioned that:

'You need to be in touch with what is going on, the changes. Things are rapidly changing, so you need to be aware of what's going on in education and in health, and politically, on education, on a whole lot of levels.'

\section{Recognising that there are contributing factors that make leaders successful (interpersonal mastery)}

Another contributing factor in becoming a successful leader is interpersonal mastery, where people learn from each other. ${ }^{[4]}$ A need was identified for interpersonal sharing of ideas through peer support:

'I think peer support is a very important thing, because I think at the moment you come into the position, and you have to deliver, but there's actually not a place where you can really go and create ideas and things like that'.

A participant stated that a two-way relationship is essential:

'I think also being in leadership the relationships are always bidirectional, it can never just come from one side? 


\section{Taking your own journey into being (being mastery)}

Self-leaders should take time to realise who they are, by reflecting on their life experience, where they have been and where they might go. ${ }^{[4]}$ One participant was of the opinion that to achieve more as a leader, one first needs to understand oneself and one's own potential as an individual:

'Myself, I think it started off with me and engaging in processes with myself to get to a point where I could understand myself. I don't think one could be an effective leader if you haven't done the work on yourself. It's like I always start my courses and say research and know thyself. Because one can never go out and know something or somebody else if you don't know yourself, so I think a lot of my drive comes from that.'

It was also mentioned that self-confidence was needed:

'I think part of leadership is about confidence within yourself and if you ... if you are solidly grounded within yourself and you confident in terms of who you are and it doesn't require somebody with a big voice.'

\section{Making choices wisely, to be effective (balance mastery)}

Mastering balance refers to recognising that every choice we make potentially also affects our work balance to survive ${ }^{[4]}$ One participant highlighted her own role in empowerment and choices in self-development:

'I know that my opinion is that I will go ahead and empower and build my knowledge and get the books and everything, my growth is in my hands. So I'm going to do it irrespectively whether someone else does it or not.'

Another participant mentioned his own role in taking wise and accountable decisions and actions:

'They should be able to take up initiatives, if nothing is happening, say at a certain level as the job's got to be done. We can't all wait for something to happen, we've got to actually, sometimes say, this is the situation, I'm accountable to staff and students and everything; if no one else is guiding me, I go out and find it.'

The importance of sharing experiences with other people also came to the fore: 'As leaders we are not prepared for all circumstances in life but if we are given an opportunity to share and in a safe space, then I feel that people will grow, because I find that I learn a lot from sharing, talking to others.

\section{Taking actions connected to purpose and vision (action mastery)}

Our inner resources and values shape our actions and behaviour in the world. Personal values shape decisions and behaviour, and are drivers in creating organisational values. ${ }^{[6]}$ The process of drawing others into a common vision was outlined:

'What comes to mind is vision [...] It's around knowing long-term where your department is heading, and how it should get there. And then, to facilitate a group of people to buy into that vision, share that vision, and be moving towards that vision.'

One participant expressed how her experiences in life had developed her as a leader:

'I think you [...] leadership skills one develops, your personal experiences in life is definitely one of the things that contribute to the development of leadership skills. Your values, and your beliefs in life also contributes to the type of leadership and then the opportunities that you have had, to be in a leadership role.

\section{Discussion}

Personal mastery is considered to be achieved when one comes to see life from a new perspective, while following the principles of having purpose, vision, belief and commitment, and knowing oneself. ${ }^{[7]}$ It seemed that through self-awareness, the participants sought new ways of doing things and shaping their environment, while encouraging their followers to be a part of the changing process. Under the mentorship model, a more experienced person provides advice and serves as a partner in developing the mentee's skills, so as to become more self-aware in situations in which leadership should be shown, and also as part of developing him/her for future leadership succession. The participants highlighted the importance of having a vision or purpose for the future. Leadership was shown in that participants indicated that they moved from problems to opportunities, that their workplace was always changing and they needed to accept this, and that they needed to adapt to change. Participants understood that to create change, it is important to have a clear vision of the future within an organisation that benefits the community it serves. Participants saw the need to create an organisational culture where people work together toward success, and this indicated their awareness of the importance of adaptability in change. This requires transformational leadership that involves the enactment of behaviours that inspire followers to perform beyond expectations. ${ }^{[8]}$ Participants found that having a vision helped leaders and their teams to become inspired and committed to a shared goal of quality education. Effective leadership is an essential attribute for the provision of professional and high-quality education.

Certain factors contribute to effective leadership, and the findings indicated that a leader cannot exist in isolation, as effective interpersonal relationships are needed. Some of these relationships are with peers, and participants mentioned that peer support could provide opportunities to develop teamwork that could enhance the quality of services rendered in the university setting. A study in Ireland ${ }^{[9]}$ also confirmed that having peers support one another, especially during challenging times, is very valuable. Support can also be seen in a two-way relationship, which could be established through consultation. Consultation is bidirectional, and provides individuals with a voice to openly exchange information, which leads to development within a group. ${ }^{[10]}$

The participants experienced their own unique journey while working in different departments as they used their intuition to lead themselves. The intuition of man informs him of the existence of 'something within' which transcends all intellectual knowledge and reasoning processes, but which is perceived to be ever-present at the very heart of one's being. ${ }^{[11]}$ One should make wise choices in an academic environment. Professional and personal development originates from one's own personal skills and expertise. ${ }^{[10]}$ People need to be encouraged to develop the skills and competencies they require to become better workers, managers, entrepreneurs and innovators, who make wise decisions. In this study, the findings indicated that 'making sense of things' was part of selfleadership that shaped how academics understood themselves and their competencies. A leader's abilities and values are related to how they structure tasks and manage the interpersonal relationships between other members of their department, which could impact the processes and ultimately the performance of a team ${ }^{[10]}$ or faculty.

\section{Conclusion}

Leadership is no longer to be found only among organisational leaders, but also among academics. All the characteristics (masteries) of self-leadership 
described in Cashman's ${ }^{[4]}$ theoretical framework were mentioned by participants. Participants were self-aware of their leadership roles, and as leaders expressed who they were as individuals, and discussed their diverse leadership experiences in the different departments. The experiences that the participants shared demonstrated a clear philosophy in the Faculty of Community and Health Sciences of focusing on leadership development and the succession of academics.

Acknowledgements. The authors would like to express gratitude to the staff members who participated in this study.

Author contributions. KJ was the main author, with creative input from JF on the theoretical framework implemented.

Funding. None.

Conflicts of interest. None.
1. Jooste K, Ahanohuo L, Arunachallam S, et al. The meaning of self-leadership for nursing academics of a research programme in the context of a higher education institution in the Western Cape. Afr J Nurs Midwifer 2015;17(1):122-133. https://doi.org/10.25159/2520-5293/238

2. Grint K. Leadership: Limits and Possibilities. Basingstoke: Palgrave Macmillan, 2005.

3. Bolden R, Gosling J, O'Brien A, et al. Academic Leadership: Changing Conceptions, Identities and Experiences in UK Higher Education. London: Leadership Foundation for Higher Education, 2012.

4. Cashman K. Leadership from the Inside Out. Provo: Executive Excellence Publishing, 1998:1-7.

5. Gerstberger RL, Gromala KA. How effective is utility leadership? J Am Water Works Assoc 2010;102(1):46-55 6. Lichtenstein S. The Role of Values in Leadership: How Leaders' Values Shape Value Creation. Integra Leadership review. http://integralleadershipreview.com/6176-the-role-of-values-in-leadership-how-leadersvalues-shape-value-creation/ (accessed 1 June 2016)

7. Baker B. What is Personal Mastery - A Look into Personal Development from a New Perspective. http:/ www.startofhappiness.com/what-is-personal-mastery (accessed 2 April 2016).

8. Walsh M, Dupré K, Arnold KA. Processes through which transformational leaders affect employee psychological health. Ger J Resear Hum Resour Manage 2014;28(1-2):162-172. https://doi.org/10.1177/239700221402800109 9. Browne P. Bi-directional work to life conflict: An investigation of work life balance for nurses in acute public hospital settings in Ireland. Doctoral thesis. Galway: National University of Ireland, Galway, 2015. . Friedrich TM, Vessey WB, Schuelke MJ. A framework for understanding collective leadership: The selective utilization of leader and team expertise within networks. Leadersh Q 2009;20(6):933-958. https://
doi.org/10.1016/j.leaqua.2009.09.008

.

. Parkinsol https://doi.org/10.1080/09614521003709957

Accepted 7 September 2016 